\title{
A Systematic Literature Review of Three Modalities in Technologically Assisted TKA
}

\author{
William A. Leone, ${ }^{1}$ Leah C. Elson, ${ }^{2}$ and Christopher R. Anderson ${ }^{2}$ \\ ${ }^{1}$ The Leone Center for Orthopedic Care, Holy Cross Hospital, 4725 N. Federal Highway, Fort Lauderdale, FL 33308, USA \\ ${ }^{2}$ Department of Bioengineering and Clinical Research, OrthoSensor Inc., 1855 Griffin Road, Suite A-310, Dania Beach, FL 33004, USA \\ Correspondence should be addressed to Christopher R. Anderson; canderson@orthosensor.com
}

Received 1 September 2015; Revised 9 October 2015; Accepted 12 October 2015

Academic Editor: Panagiotis Korovessis

Copyright (C) 2015 William A. Leone et al. This is an open access article distributed under the Creative Commons Attribution License, which permits unrestricted use, distribution, and reproduction in any medium, provided the original work is properly cited.

In effort to reduce the revision burden of total knee arthroplasty (TKA), industry emphasis has focused on replacing manual techniques - which are subject to variability-with technological implements. Unfortunately, technological innovation often continues before adequate time for critical evaluation has passed. Therefore, the purpose of this descriptive literature review was to collect a large sample of international data and report on the clinical and economic efficacy of three major types of technologically assisted TKA: navigation, patient-specific instrumentation, and sensorized trials.

\section{Introduction}

Today, digitized tools have become a mainstay in orthopaedic operating rooms around the world. A transition away from manual techniques has been implemented in order to develop new ways to attempt to reduce the proportion of revision total knee arthroplasty (TKA) procedures performed annually. Currently, the United States bears a 2.7-billion-dollar TKA revision burden, a value that has not undergone appreciable decrease in the last decade [1]. Thus, many orthopaedic specialists have looked to intraoperative technological assistance with the hope of reducing the incidence of surgeon-driven error, including component alignment, although it is still unclear if alignment outliers lead to increased revision rates $[2,3]$.

However, innovation often continues before existing technology has been sufficiently critically evaluated. With more drastic financial restrictions being placed on operating room spending, orthopaedic surgeons are now required to provide excellent results on a budget.

It is integral that both clinical efficacy and cost-effectiveness of these intraoperative technologies be fully understood in order to provide patients with effectual, economically conscious care. Therefore, the purpose of this qualitative analysis of literature was to evaluate clinical and economic efficacy of the three most prominent technologies currently used in TKA: computer navigation, patient-specific instrumentation, and kinetic sensors.

\section{Methods}

A systematic literature review was conducted between September 1, 2014, and September 15, 2014. Using PubMed, combinations of the following keywords were queried: "patient specific instrumentation", "patient matched instrumentation", "patient specific cutting blocks", "computer-assisted surgery”, "computer navigation”, “TKA”, "total knee arthroplasty", "sensors", "history", "cost", "outcomes", and "satisfaction," in the following strings: "patient specific total knee arthroplasty", "computer navigation total knee arthroplasty," "sensor total knee arthroplasty", "patient matched instrumentation TKA," "patient specific cutting blocks TKA", "cost sensors TKA", "cost patient specific instrumentation TKA", "cost patient matched instrumentation TKA", "cost patient specific cutting blocks TKA", "outcomes patient specific instrumentation TKA", "outcomes patient matched TKA", "outcomes sensors TKA", "outcomes computer navigation TKA", "satisfaction computer navigation TKA", "satisfaction sensors TKA", "satisfaction patient specific instrumentation 


\begin{tabular}{|c|c|}
\hline Identification & $\begin{array}{c}393 \text { articles identified through } \\
\text { PubMed search }\end{array}$ \\
\hline Screening & 97 screened \\
\hline Eligibility & 94 met inclusion $\begin{array}{c}296 \text { duplicates } \\
\text { removed }\end{array}$ \\
\hline $\begin{array}{c}\text { criteria } \\
\text { inclusion criteria }\end{array}$ \\
\hline inclusion
\end{tabular}

FIGURE 1

TKA," "satisfaction patient matched TKA", "satisfaction patient specific cutting blocks TKA", "history sensors TKA," "history computer navigation TKA", "history patient specific cutting blocks TKA," and "history patient specific instrumentation."

Three hundred and ninety-three publications were collected; 94 were included in final qualitative analysis as per Figure 1. The level of evidence for all harvested publications was as follows: Level 1/Level 2: 52\%; Level 3 (all retrospective analyses): 14\%; Level 4: 31\%; Level 5: 3\% (all biomechani$\mathrm{cal} /$ cadaveric testing). Criteria for inclusion in the analysis were defined only insofar as each piece assessed one of the above listed aspects of patient-specific instrumentation, computer navigation, and/or intraoperative sensors. Literature included in the final evaluation contained background information on each respective technology, clinical outcomes, revision rates, and/or cost analyses. All comparisons were conducted in a strictly qualitative manner, and no attempts were made to conduct interstudy statistical analyses due to the high level of variability in methodology and data collected.

\section{Results}

3.1. Computer Navigation. Computer navigation (also called "CAOS" or "computer-assisted orthopaedic surgery") was developed in order to increase the accuracy of bony resection, while simultaneously decreasing the incidence of positioning outliers. The first documented case of the use of computer navigation, in TKA, was in 1997 [4]. Since then, a variety of navigation systems have been developed.

All systems can be classified into two, broad categories: those which are compatible with specific instrumentation (typically referred to as "closed systems") or those which can be used regardless of component type or manufacturer (typically referred to as "open systems") [5]. Navigation is also classified by its method of anatomic mapping, which can be accomplished by CT, fluoroscopy, or imageless means. Each system uses images obtained from the patient (or, in the case of imageless systems, images obtained from a large database), to construct a three-dimensional model of preoperative bony anatomy.

When the patient enters surgery, registration of markers or reflectors is used to define points in space based on the three-dimensional anatomical model. The computer navigation software triangulates the location of each marker and the markers, collectively, provide information regarding location of anatomic landmarks, mechanical axes, component positioning, and center of rotation. Accurate placement of all marker pins in the distal femur and proximal tibia is absolutely crucial for the computer reconstruction of native anatomy.

A survey, conducted by Friederich and Verdonk $(n=3,330$ surgeons; Swiss Orthopedic Society and European Society of Sports Traumatology Knee Surgery and Arthroscopy) demonstrated that one-third of surgeons use navigation for approximately half of their cases, while one-quarter of surgeons use navigation for over $75 \%$ of their cases [6]. Australian Joint Registry data reports a similar proportion of usage: 2015 Hip and Knee Arthroplasty Annual Report indicates $29 \%$ of total knee replacements, nationwide, were performed with CAOS. The operative advantages in using navigation to guide TKA are the objective parameters with which bone cuts are made. The accuracy available for obtaining a symmetrical joint gap may also theoretically allow for more balanced soft-tissues [5].

Yet, the results of alignment and positioning have not been consistently reported in literature. While many surgeons agree that navigation allows for more accuracy in component alignment, others argue that no significant difference has been noted when compared with manual medullary techniques [7-35]. For instance, a group of 160 bilateral patientsone knee operated with navigation; one knee operated with manual techniques-showed that there was no significant difference with respect to alignment [26]. Yet, a metaanalysis, conducted by Hetaimish et al. contends that an evaluation of 23 publications agree that positioning outliers are greatly reduced with the use of navigation [36].

However, even with confirmed alignment accuracy, the clinical outcomes of patients present another aspect of navigation that is widely debated $[7,9,13,18,20,24,31,37-$ 44]. Many surgeons have made note of marked improvement in groups of navigated patients. A survivorship analysis, performed by Hakki et al., showed a lack of revision surgery required in navigated TKAs, at 5 years, while the nonnavigated group showed a $2.8 \%$ revision rate at the same time interval $(n=100)$ [39]. Another publication, using data from the Australian registry, shows reduced revision rates, in patients younger than 65 years, who have undergone navigated TKA [45]. Yet, other surgeons have reported no major difference in outcomes measures when compared with manual TKA (Figure 2). A recent study from 2014 showed no difference in navigated versus nonnavigated survivorship duration, KSS outcomes measures, and HSS outcomes measures at 5 years postoperatively [15].

Beyond an overall divided opinion on the effectiveness of navigation, the price point of navigation is also quite high. The price of a typical system is calculated in a piecemeal fashion: cost of the computer, cost of the software, and cost of an annual service contract from the manufacturer. In total, the dues of navigation equipment, per year, can reach upwards of $\$ 45,000$ dollars [46-48]. Many surgeons have attempted to analyze the cost-effectiveness by assessing the frequency of use. Three particular evaluations have noted that navigation systems have the potential to be cost-effective, but 


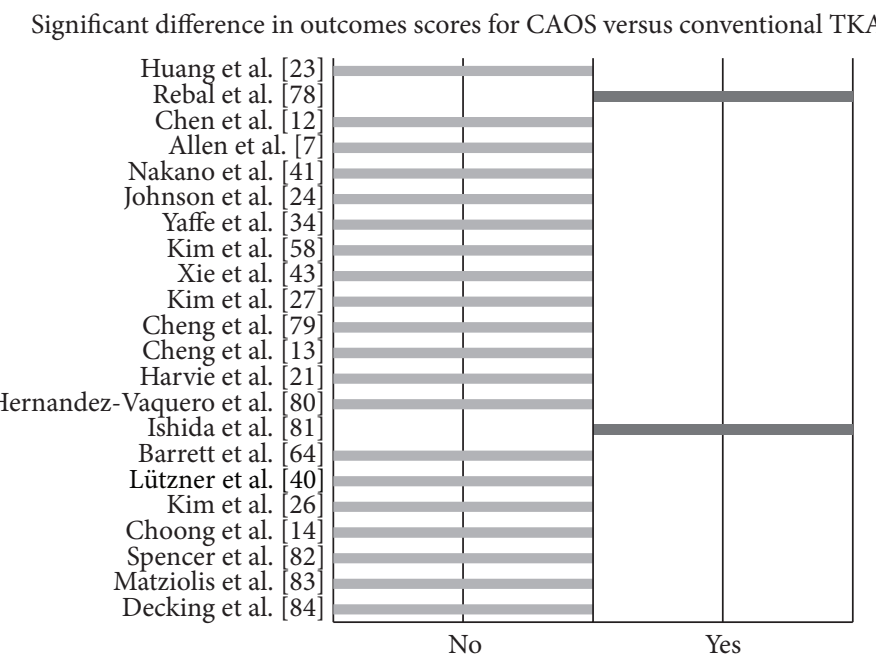

FIGURE 2

only in high-volume medical centers $[47,49,50]$. Still, a paper by Gøthesen et al. contends that the purchase of a navigation package is only cost-effective at high-volume centers, if it proves to significantly decrease revision rates [46]. On a costper-case basis, navigation has been shown to contribute to an additional $\$ 1,500$ per procedure [47].

3.2. Patient-Specific Instrumentation. Due to the impact of high costs associated with navigation and the complex protocol associated with registering markers, patient-specific instrumentation (PSI) was developed to increase cutting accuracy, decrease the amount of surgical trays required, and simplify cutting procedures.

This intraoperative technology was introduced in the first decade of the 21st century [51,52] and is now available through six separate manufacturers [52]. PSI usage begins with preoperative imaging, which can combine CT, MRI, and/or a standing anteroposterior radiograph. A threedimensional model is constructed from the amalgam of imaging techniques and a positioning algorithm (specific to each manufacturer) is applied to determine the correct positioning for the tibial and femoral components. This preoperative plan is then sent to the surgeon for approval. Once the surgeon has confirmed the preoperative plan, the PSI is rendered into the physical cutting jig system. Intraoperatively, the femoral guide is clicked into place and is used to determine sizing, level of resection, rotation, and anteroposterior positioning. Similarly, the tibial guide assists in the determination of tibial alignment, rotation, level of resection, and slope. The multifaceted capability of the PSI system eliminates several steps normally attributed to femoral and tibial preparation, theoretically increasing operating room efficiency [53].

Several studies have confirmed that the truncation of steps associated with using PSI does decrease operative time [54-59]. One particular study noted an average 20-minute decrease in operating room time, when compared with manual TKA [60].
In addition to the general consensus on time saving, many authors also agree that alignment with PSI is often inaccurate or exhibits a larger proportion of outliers than conventional TKA $[61,62]$. One particular evaluation noted no difference between PSI and conventional method alignment in femoral coronal and femoral axial planes but a marked increase in PSI outliers in both the coronal and sagittal tibial planes $(n=128)$ [63]. Another study observed a $21 \%$ increase in hipknee-ankle angle outliers with the use of PSI, when compared with conventional methods [61]. A majority of studies have indicated that PSI is either as accurate as or less accurate than conventional TKA or navigation systems [50, 58, 64-73].

A consensus on inaccuracy might beg the question: why? If the cutting jigs are custom-rendered to fit each patient's specific bony morphology, where does the incidence of inaccuracy originate from? Several surgeons sought to answer this question, and many of them observed that the preoperative plan did not match the final, physical rendering used in the operating room [62, 74-76]. One particular study, conducted by Scholes et al., noted that $27 \%$ of the PSI cutting jigs, received in surgery, induced coronal error in excess of $3^{\circ}$ [76]. Another study also showed that $77 \%$ of femurs, and $54 \%$ of tibias, required intraoperative resizing due to lack of fit [62]. The authors of these studies came to similar conclusions: because there are several steps associated with creating the jigs, there is opportunity for error. Due to the process associated with rendering PSI (imaging, model creation, planning, and manufacturing), involving the surgeon and manufacturing engineers, small errors may culminate in ineffective cutting jigs. All authors have advised that great care be taken on part of the surgeon when approving the preoperative plans and avoiding using PSI in any procedure without prior approval of jig schematics [62, 74-76].

Evidence surrounding the clinical outcomes of PSI is sparse. However, much of it draws similar conclusions. One study noted that there seemed to be improved postoperative kinematics, when compared with manual TKA, but there was no difference in KSS, quality of life, KOOS, or SF-12 scores 


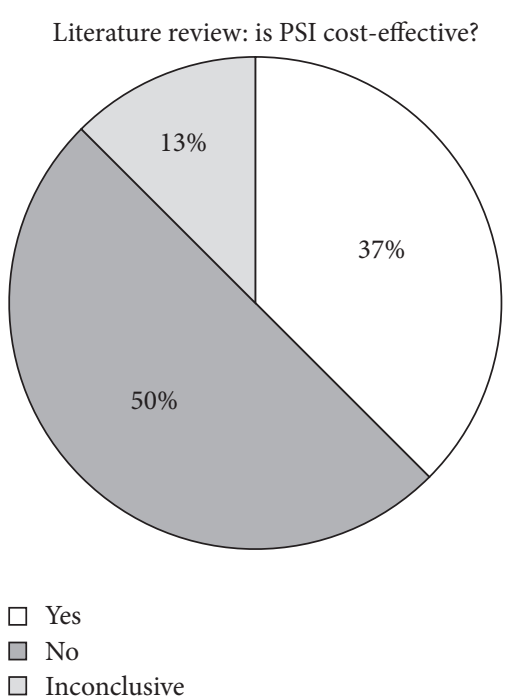

Figure 3

[77]. Another study indicated that the tibial slope exhibited more precision in PSI patients, but their blood loss, pain, satisfaction, and functional outcomes were comparable to manual TKA patients [73]. The only study from this evaluation that noted a higher postoperative functional improvement, in PSI patients, also indicated that the preoperative scores were higher to begin with, thus being inconclusive evidence for improvement [34].

Cost-effectiveness for PSI can be evaluated in several ways; PSI may reduce operative time, requires less equipment, and is less expensive instrumentally. However, much of the literature is also divided on the validity of these claims (Figure 3). Several studies indicate that PSI is cost-effective $[57,59,60,85,86]$. One study, by Lionberger et al., showed that the time saved in using PSI allows for an increased volume of procedures, citing that 3 PSI procedures can be completed for every 2 navigated procedures, resulting in a $1.45 \mathrm{x}$ increased profit [85]. Several more studies observe that PSI is not cost-effective $[75,87,88]$. One study contends that while there were fewer trays required for the procedure, the inaccuracy of the cutting jigs required more work intraoperatively, thereby negatively impacting the operating room efficiency [75]. On a cost-per-case basis, PSI has been shown to contribute upwards of $\$ 1,000$ per procedure in vendor charges to the hospital (cost of fabrication of cutting blocks) and includes up to $\$ 1,000$ dollars in additional charges for imaging $[58,88,89]$.

3.3. Intraoperative Sensors. Correct alignment in TKA only represents a portion of operative factors that contribute to component survivorship and patient satisfaction. In effort to quantify soft-tissue balance, intraoperative kinetic sensors have been developed to dynamically guide surgeons through ligament release. This technology is the most recent innovation in TKA and has been introduced within the last 10 years [90].
Kinetic sensor systems are composed of a sensor (a small housing containing a microprocessing unit and mediallateral force plates) and a software system which provides the surgeon with dynamic, visual output of force vectors and tibiofemoral contact point location. The sensor fits into the tibial baseplate and is used to track loading values as the surgeon guides the knee joint through a range of motion. Using the visual output, the surgeon can selectively resect more bone or release soft-tissues in order to quantifiably balance the knee. Additionally, using the tibiofemoral contact point positions, in both the medial and lateral compartments, relative to one another, measurements of tibial tray rotation can be captured and corrected [91, 92]. No additional time is necessary in using the sensor, and it has not been reported to disrupt surgical workflow $[91,92]$.

Studies have confirmed that kinetic sensors are sensitive enough to measure force differentials as small as $1 \mathrm{lb}$. per square inch and with error margins within 1.5\% [93]. Furthermore, these same studies have also confirmed that subtle imbalance, as detected by the sensor, can be seen clinically. A study by Wasielewski et al. used fluoroscopic imaging to demonstrate that imbalance detected by the sensor manifests as unfavorable kinematics during gait [94]. Another study showed that initial placement of the sensor displayed imbalance in all knees tested and that the sensor substantially reduced imbalance before closure [95].

While only recent articles exist regarding clinical efficacy of such a new technology, the research available suggests favorable clinical outcomes associated with using kinetic sensors to achieve balance, at both short- and long-term intervals. One multicentric study, by Gustke et al., showed postoperative improvement in WOMAC, KSS, and activity level scores in patients balanced with sensor assistance [96]. Another study showed further significant improvement, for the same group of multicenter patients at 1 year and for patient satisfaction $[89,97]$. There was also an observed trend towards clinically relevant weight loss (weight loss $>6 \mathrm{lbs}$.) in a group of patients balanced with sensor assistance when compared with literature-reported values [98].

One particular study evaluating a specific sensor type claims that the sensor is both disposable and priced under $\$ 1,000$ per case and currently available with several total knee systems, although this pricing schema has not been confirmed elsewhere [99].

When comparing outcomes qualitatively, the Knee Society Score (KSS) was the most frequently reported metric for all three technologies and gave the authors a consistent point of comparison, with a follow-up of one or two years postoperatively. Kinetic sensors appeared to offer the highest increase in KSS scores and lowest cost-per-case. PSI data showed the second-highest increase in KSS scores but the most costly increase in excess procedural fees. CAOS was associated with the least highest increase in KSS and the second-highest cost-per-case [12, 19, 27, 46-49, 52, 54, 60, 85, 88, 99-101]. However, high quality, long-term, randomized trials for kinetic sensors have not yet been published and will be essential for a more thorough understanding of any clinical efficacy. Furthermore, quality adjusted life years analyses will 
also be required to understand the cost-effectiveness, as a function of health, for these devices.

\section{Discussion}

Advances in electrical engineering have made it possible for surgeons to use technology to reduce the subjectivity associated with TKA procedures. Currently, technological innovation is being driven with the hope of dramatically reducing the crippling 2.7-billion-dollar revision burden in the United States [1]. However, many of these novel devices are developed before a thorough understanding of the clinical and economic implications of prior devices is fully made. Therefore, it is imperative that overall efficacy of these technologies is explored and considered before implementing them into a clinical setting.

Three prominent technologies are used in modern orthopaedic operating rooms, including computer navigation, patient-specific instrumentation, and kinetic sensors. Navigation has been on the market for the longest duration of time, followed by patient-specific instrumentation and finally-the newest device-kinetic sensors. Each device has been developed with the goal of improving the accuracy of operative procedures and increasing patient satisfaction.

Navigation was designed to reduce alignment and component positioning outliers. While many surgeons have vouched for its precision $[20,25,29,36,79]$, many more have argued that its results are no better than that achieved by manual techniques [7, 12, 102, 103]. Further divided is the topic of clinical outcomes. Studies have shown that clinical outcomes have improved in navigated TKA patients [14, 30, $39,42]$, but an abundance of research suggests that this is not the case $[11,13,15,22,24,26,38,40,41,43,44]$. In consideration of the expense of this technology [47, 48], coupled with inconclusive results, navigation does not, at this time, seem to fit the schema for significantly reducing the rate of revision and operative cost.

Patient-specific instrumentation was designed to reduce the expense of navigation systems, simplify computerassisted methods, and improve functional outcomes [53]. However, a majority of research has suggested that PSI is either no better, or even worse, at alignment accuracy than manual techniques $[50,58,61,63-73,104]$. This inability to consistently reduce positioning outliers may be a product of the convoluted system with which each PSI is rendered [74$76,104]$. Because of this, many surgeons have reported that PSI actually increases operative time by disrupting workflow [75]. Also, very few publications have been able to attest to any significant increase in functional outcomes scores of PSI patients, over the scores of navigation or manual TKA $[34,73]$. Perhaps with further refining of the PSI rendering process, accuracy can be improved. However, PSI currently does not prove to reduce TKA complications or decrease operating room costs $[75,87,88]$.

Finally, kinetic sensor technology has been engineered to quantify soft-tissue balance, improve rotational alignment, and decrease the risk of postoperative complications. The margin of error for detecting loads has been shown to be low
[93]; the sensors may be able to measure subtle imbalance that leads to altered gait kinematics [94] and has shown improvement in several patient-reported outcomes measures in balanced patients $[55,96,99,100]$. This technology may prove to be promising in that it does not add appreciable time to surgical workflow and may also be cost-effective [91, 92, 99].

There were limitations to this literature review. (1) There was no quantitative analysis performed. The variability and scope of topics and procedures discussed would make confounding standardization difficult, statistically. Thus, in order to keep the evaluation simple, and mitigate the risk of an improper application of statistics, analyses were limited to qualitative modalities. (2) Robotic total knee arthroplasty is not reviewed. Although this is an additional technological innovation it is not available for all major knee systems. As such, the authors sought to compare modalities that could be applied to the largest base of component types for applicability to the readers. (3) There is limited economic and clinical data for the sensor modality. Because this is the most recent implement for total knee arthroplasty, Level I research evaluations have yet to be published, and the longest published follow-up interval is at 1 year. However, the authors thought it important to include sensorized data because it is the only modality that assists the surgeon in evaluation of soft-tissue, exclusively, is novel in its disposability, and thus represents a stark contrast to PSI or CAOS for comparison purposes.

If innovation is directed responsibly, both clinical efficacy and cost-effectiveness are attainable for the future of TKA. This review shows some technologies may not yield a clinical or time-saving payoff for the patient and hospital. While kinetic sensor devices seem to be the most promising modality, much more research will be necessary to confirm its advantages over time. But, great care must be taken when adopting any novel technology; "new" does not always mean "improved."

\section{Conflict of Interests}

William A. Leone is a paid consultant for OrthoSensor, Inc., but has not received institutional funding to conduct this research. Leah C. Elson and Christopher R. Anderson are paid employees of OrthoSensor, Inc.

\section{References}

[1] M. Bhandari, J. Smith, L. E. Miller, and J. E. Block, "Clinical andeconomic burden of revision knee arthroplasty," Clinical Medicine Insights: Arthritis and Musculoskeletal Disorders, vol. 5, pp. 89-94, 2012.

[2] S. Parratte, M. W. Pagnano, R. T. Trousdale, and D. J. Berry, "Effect of postoperative mechanical axis alignment on the fifteen-year survival of modern, cemented total knee replacements," The Journal of Bone \& Joint Surgery - American Volume, vol. 92, no. 12, pp. 2143-2149, 2010.

[3] K. Gromov, M. Korchi, M. G. Thomsen, H. Husted, and A. Troelsen, "What is the optimal alignment of the tibial and 
femoral components in knee arthroplasty?" Acta Orthopaedica, vol. 85, no. 5, pp. 480-487, 2014.

[4] K. A. Krackow, L. Serpe, M. J. Phillips, M. Bayers-Thering, and W. M. Mihalko, "A new technique for determining proper mechanical axis alignment during total knee arthroplasty: progress toward computer-assisted TKA," Orthopedics, vol. 22, no. 7, pp. 698-702, 1999.

[5] D. K. Bae and S. J. Song, "Computer assisted navigation in knee arthroplasty," Clinics in Orthopedic Surgery, vol. 3, no. 4, pp. 259-267, 2011.

[6] N. Friederich and R. Verdonk, "The use of computer-assisted orthopedic surgery for total knee replacement in daily practice: a survey among ESSKA/SGO-SSO members," Knee Surgery, Sports Traumatology, Arthroscopy, vol. 16, no. 6, pp. 536-543, 2008.

[7] C. L. Allen, G. J. Hooper, B. J. Oram, and J. E. Wells, "Does computer-assisted total knee arthroplasty improve the overall component position and patient function?" International Orthopaedics, vol. 38, no. 2, pp. 251-257, 2014.

[8] K. Bauwens, G. Matthes, M. Wich et al., "Navigated total knee replacement: a meta-analysis," The Journal of Bone \& Joint Surgery-American Volum, vol. 89, no. 2, pp. 261-269, 2007.

[9] W. G. Blakeney, R. J. K. Khan, and J. L. Palmer, "Functional outcomes following total knee arthroplasty: a randomised trial comparing computer-assisted surgery with conventional techniques," Knee, vol. 21, no. 2, pp. 364-368, 2014.

[10] Y. S. Brin, V. S. Nikolaou, L. Joseph, D. J. Zukor, and J. Antoniou, "Imageless computer assisted versus conventional total knee replacement. A Bayesian meta-analysis of 23 comparative studies," International Orthopaedics, vol. 35, no. 3, pp. 331-339, 2011.

[11] R. S. J. Burnett and R. L. Barrack, "Computer-assisted total knee arthroplasty is currently of no proven clinical benefit: a systematic review," Clinical Orthopaedics and Related Research, vol. 471, no. 1, pp. 264-276, 2013.

[12] X. Chen, H. Wang, Y. Cai, Q. Zhu, and J. Zhu, "Sagittal component alignment is less reliable than coronal component alignment in a Chinese population undergoing navigated TKA," Journal of Orthopaedic Surgery and Research, vol. 9, no. 51, pp. $1-7,2014$.

[13] T. Cheng, X.-Y. Pan, X. Mao, G.-Y. Zhang, and X.-L. Zhang, "Little clinical advantage of computer-assisted navigation over conventional instrumentation in primary total knee arthroplasty at early follow-up," The Knee, vol. 19, no. 4, pp. 237-245, 2012.

[14] P. F. Choong, M. M. Dowsey, and J. D. Stoney, "Does accurate anatomical alignment result in better function and quality of life? Comparing conventional and computer-assisted total knee arthroplasty," Journal of Arthroplasty, vol. 24, no. 4, pp. 560-569, 2009.

[15] J. Cip, M. Widemschek, M. Luegmair, M. B. Sheinkop, T. Benesch, and A. Martin, "Conventional versus computerassisted technique for total knee arthroplasty: a minimum of 5 -year follow-up on 200 patients in a prospective randomized trial," Journal of Arthroplasty, vol. 29, no. 9, pp. 1795-1802, 2014.

[16] A. S. Desai, A. Dramis, D. Kendoff, and T. N. Board, "Critical review of the current practice for computer-assisted navigation in total knee replacement surgery: cost-effectiveness and clinical outcome," Current Reviews in Musculoskeletal Medicine, vol. 4, no. 1, pp. 11-15, 2011.

[17] J. Dexel, S. Kirschner, K. P. Günther, and J. Lützner, "Agreement between radiological and computer navigation measurement of lower limb alignment," Knee Surgery, Sports Traumatology, Arthroscopy, vol. 22, no. 11, pp. 2721-2727, 2014.

[18] G. S. Dyrhovden, O. Gothesen, S. H. L. Lygre et al., "Is the use of computer navigation in total knee arthroplasty improving implant positioning and function? A comparative study of 198 knees operated at a Norwegian district hospital," BMC Musculoskeletal Disorders, vol. 14, article 321, 2013.

[19] G. Ee, H. N. Pang, H. C. Chong, M. H. Tan, N. N. Lo, and S. J. Yeo, "Computer navigation is a useful intra-operative tool for joint line measurement in total knee arthroplasty," The Knee, vol. 20, no. 4, pp. 256-262, 2013.

[20] A. Ensini, F. Catani, A. Leardini, M. Romagnoli, and S. Giannini, "Alignments and clinical results in conventional and navigated total knee arthroplasty," Clinical Orthopaedics and Related Research, no. 457, pp. 156-162, 2007.

[21] P. Harvie, K. Sloan, and R. J. Beaver, "Computer navigation vs conventional total knee arthroplasty. five-year functional results of a prospective randomized trial," Journal of Arthroplasty, vol. 27, no. 5, pp. 667-672.e1, 2012.

[22] C. M. Hiscox, E. R. Bohm, T. R. Turgeon, D. R. Hedden, and C. D. Burnell, "Randomized trial of computer-assisted knee arthroplasty: impact on clinical and radiographic outcomes," Journal of Arthroplasty, vol. 26, no. 8, pp. 1259-1264, 2011.

[23] T.-W. Huang, L.-T. Kuo, K.-T. Peng, M. S. Lee, and R. W.-W. Hsu, "Computed tomography evaluation in total knee arthroplasty: computer-assisted navigation versus conventional instrumentation in patients with advanced valgus arthritic knees," The Journal of Arthroplasty, vol. 29, no. 12, pp. 2363-2368, 2014.

[24] D. R. Johnson, D. A. Dennis, K. A. Kindsfater, and R. H. Kim, "Evaluation of total knee arthroplasty performed with and without computer navigation: a bilateral total knee arthroplasty study," Journal of Arthroplasty, vol. 28, no. 3, pp. 455-458, 2013.

[25] Y. D. Kamat, K. M. Aurakzai, and A. R. Adhikari, "Total knee replacement in the obese patient: comparing computer assisted and conventional technique," The Scientific World Journal, vol. 2014, Article ID 272838, 5 pages, 2014.

[26] Y.-H. Kim, J.-S. Kim, Y. Choi, and O.-R. Kwon, "Computerassisted surgical navigation does not improve the alignment and orientation of the components in total knee arthroplasty," The Journal of Bone \& Joint Surgery -American Volume, vol. 91, no. 1, pp. 14-19, 2009.

[27] Y.-H. Kim, J.-W. Park, and J.-S. Kim, “Computer-navigated versus conventional total knee arthroplasty: a prospective randomized trial," The Journal of Bone \& Joint Surgery-American Volume, vol. 94, no. 22, pp. 2017-2024, 2012.

[28] J. B. Mason, T. K. Fehring, R. Estok, D. Banel, and K. Fahrbach, "Meta-analysis of alignment outcomes in computer-assisted total knee arthroplasty surgery," The Journal of Arthroplasty, vol. 22, no. 8, pp. 1097-1106, 2007.

[29] J. B. Mason, T. K. Fehring, R. Estok, D. Banel, and K. Fahrbach, "Meta-analysis of alignment outcomes in computer-assisted total knee arthroplasty surgery," The Journal of Arthroplasty, vol. 22, no. 8, pp. 1097-1106, 2007.

[30] M. F. Meijer, I. H. F. Reininga, A. L. Boerboom, S. K. Bulstra, and M. Stevens, "Does imageless computer-assisted TKA lead to improved rotational alignment or fewer outliers? A systematic review," Clinical Orthopaedics and Related Research, vol. 472, no. 10, pp. 3124-3133, 2014.

[31] M. Roche, L. Elson, and C. Anderson, "Dynamic soft tissue balancing in total knee arthroplasty," Orthopedic Clinics of North America, vol. 45, no. 2, pp. 157-165, 2014. 
[32] C. Disco and B. van der Meulen, Getting New Technologies Together, Walter de Gruyter, New York, NY, USA, 1998.

[33] C. Schnurr, U. Münnich, P. Eysel, and D. P. König, "Computerassisted joint replacement surgery," Versicherungsmedizin, vol. 62, no. 1, pp. 16-19, 2010.

[34] M. Yaffe, M. Luo, N. Goyal et al., "Clinical, functional, and radiographic outcomes following total knee arthroplasty with patient-specific instrumentation, computer-assisted surgery, and manual instrumentation: a short-term follow-up study," International Journal of Computer Assisted Radiology and Surgery, vol. 9, no. 5, pp. 837-844, 2013.

[35] L. A. Zamora, K. J. Humphreys, A. M. Watt, D. Forel, and A. L. Cameron, "Systematic review of computer-navigated total knee arthroplasty," ANZ Journal of Surgery, vol. 83, no. 1-2, pp. 22-30, 2013.

[36] B. M. Hetaimish, M. M. Khan, N. Simunovic, H. H. Al-Harbi, M. Bhandari, and P. K. Zalzal, "Meta-analysis of navigation vs conventional total knee arthroplasty," The Journal of Arthroplasty, vol. 27, no. 6, pp. 1177-1182, 2012.

[37] S. H. Ajwani, M. Jones, J. W. Jarratt, G. J. Shepard, and W. G. Ryan, "Computer assisted versus conventional total knee replacement: a comparison of tourniquet time, blood loss and length of stay," Knee, vol. 19, no. 5, pp. 606-610, 2012.

[38] Ø. Gøthesen, B. Espehaug, L. Havelin, G. Petursson, and O. Furnes, "Short-term outcome of 1,465 computer-navigated primary total knee replacements 2005-2008," Acta Orthopaedica, vol. 82, no. 3, pp. 293-300, 2011.

[39] S. Hakki, K. J. Saleh, A. G. Potty, V. Bilotta, and D. Oliveira, "Columbus navigated TKA system: clinical and radiological results at a minimum of 5 years with survivorship analysis," Orthopedics, vol. 36, no. 3, pp. e308-e318, 2013.

[40] J. Lützner, J. Dexel, and S. Kirschner, "No difference between computer-assisted and conventional total knee arthroplasty: five-year results of a prospective randomised study," Knee Surgery, Sports Traumatology, Arthroscopy, vol. 21, no. 10, pp. 2241-2247, 2013.

[41] N. Nakano, T. Matsumoto, K. Ishida, N. Tsumura, R. Kuroda, and M. Kurosaka, "Long-term subjective outcomes of computer-assisted total knee arthroplasty," International Orthopaedics, vol. 37, no. 10, pp. 1911-1915, 2013.

[42] C. Schnurr, I. Güdden, P. Eysel, and D. P. König, "Influence of computer navigation on TKA revision rates," International Orthopaedics, vol. 36, no. 11, pp. 2255-2260, 2012.

[43] C. Xie, K. Liu, L. Xiao, and R. Tang, "Clinical outcomes after computer-assisted versus conventional total knee arthroplasty," Orthopedics, vol. 35, no. 5, pp. e647-e653, 2012.

[44] M. Yaffe, P. Chan, N. Goyal, M. Luo, M. Cayo, and S. D. Stulberg, "Computer-assisted versus manual TKA: no difference in clinical or functional outcomes at 5-year follow-up," Orthopedics, vol. 36, no. 5, pp. 627-632, 2013.

[45] R. N. de Steiger, Y. L. Liu, and S. E. Graces, "Computer navigation for total knee arthroplasty reduces the revision rate in patients less than sixty-five years of age," The Journal of Bone \& Joint Surgery-American Volume, vol. 97, no. 8, pp. 635-642, 2015.

[46] Ø. Gøthesen, J. Slover, L. Havelin, J. E. Askildsen, H. Malchau, and O. Furnes, "An economic model to evaluate costeffectiveness of computer assisted knee replacement surgery in Norway," BMC Musculoskeletal Disorders, vol. 14, article 202, 2013.

[47] E. J. Novak, M. D. Silverstein, and K. J. Bozic, "The costeffectiveness of computer-assisted navigation in total knee arthroplasty," The Journal of Bone \& Joint Surgery-American Volume, vol. 89, no. 11, pp. 2389-2397, 2007.

[48] J. D. Slover, A. N. A. Tosteson, K. J. Bozic, H. E. Rubash, and $\mathrm{H}$. Malchau, "Impact of hospital volume on the economic value of computer navigation for total knee replacement," The Journal of Bone and Joint Surgery-American Volume, vol. 90, no. 7, pp. 1492-1500, 2008.

[49] D. C. Beringer, J. J. Patel, and K. J. Bozic, "An overview of economic issues in computer-assisted total joint arthroplasty," Clinical Orthopaedics and Related Research, no. 463, pp. 26-30, 2007.

[50] S. Barke, E. Musanhu, C. Busch, G. Stafford, and R. Field, "Patient-matched total knee arthroplasty: does it offer any clinical advantages?" Acta Orthopaedica Belgica, vol. 79, no. 3, pp. 307-311, 2013.

[51] S. M. Howell, K. Kuznik, M. L. Hull, and R. A. Siston, "Results of an initial experience with custom-fit positioning total knee arthroplasty in a series of 48 patients," Orthopedics, vol. 31, no. 9, pp. 857-864, 2008.

[52] P. F. Lachiewicz and R. A. Henderson, "Patient-specific instruments for total knee arthroplasty," Journal of the American Academy of Orthopaedic Surgeons, vol. 21, no. 9, pp. 513-518, 2013.

[53] M. P. Ast, D. Nam, and S. B. Haas, "Patient-specific instrumentation for total knee arthroplasty: a review," Orthopedic Clinics of North America, vol. 43, no. 5, pp. e17-e22, 2012.

[54] R. L. Barrack, E. L. Ruh, B. M. Williams, A. D. Ford, K. Foreman, and R. M. Nunley, "Patient specific cutting blocks are currently of no proven value," The Journal of Bone and Joint SurgeryBritish Volume, vol. 94, no. 11, pp. 95-99, 2012.

[55] H. Fu, J. Wang, S. Zhou et al., "No difference in mechanical alignment and femoral component placement between patientspecific instrumentation and conventional instrumentation in TKA," Knee Surgery, Sports Traumatology, Arthroscopy, vol. 23, no. 11, pp. 3288-3295, 2015.

[56] S. J. MacDessi, B. Jang, I. A. Harris, E. Wheatley, C. Bryant, and D. B. Chen, "A comparison of alignment using patient specific guides, computer navigation and conventional instrumentation in total knee arthroplasty," The Knee, vol. 21, no. 2, pp. 406-409, 2014.

[57] J. W. Noble, C. A. Moore, and N. Liu, "The value of patientmatched instrumentation in total knee arthroplasty," Journal of Arthroplasty, vol. 27, no. 1, pp. 153-155, 2012.

[58] S. H. Kim, H.-J. Lee, H.-J. Jung, J. S. Lee, and K. S. Kim, “Less femoral lift-off and better femoral alignment in TKA using computer-assisted surgery," Knee Surgery, Sports Traumatology, Arthroscopy, vol. 21, no. 10, pp. 2255-2262, 2013.

[59] T. S. Watters, R. C. Mather III, J. A. Browne, K. R. Berend, A. V. Lombardi Jr., and M. P. Bolognesi, "Analysis of procedurerelated costs and proposed benefits of using patient-specific approach in total knee arthroplasty," Journal of Surgical Orthopaedic Advances, vol. 20, no. 2, pp. 112-116, 2011.

[60] A. M. DeHaan, J. R. Adams, M. L. DeHart, and T. W. Huff, "Patient-specific versus conventional instrumentation for total knee arthroplasty: peri-operative and cost differences," The Journal of Arthroplasty, vol. 29, no. 11, pp. 2065-2069, 2014.

[61] J. Y. Chen, S. J. Yeo, A. K. S. Yew et al., "The radiological outcomes of patient-specific instrumentation versus conventional total knee arthroplasty," Knee Surgery, Sports Traumatology, Arthroscopy, vol. 22, no. 3, pp. 630-635, 2014.

[62] B. M. Stronach, C. E. Pelt, J. A. Erickson, and C. L. Peters, "Patient-specific instrumentation in total knee arthroplasty 
provides no improvement in component alignment," Journal of Arthroplasty, vol. 29, no. 9, pp. 1705-1708, 2014.

[63] J. Victor, J. Dujardin, H. Vandenneucker, N. Arnout, and J. Bellemans, "Patient-specific guides do not improve accuracy in total knee arthroplasty: a prospective randomized controlled trial," Clinical Orthopaedics and Related Research, vol. 472, no. 1, pp. 263-271, 2014.

[64] W. Barrett, D. Hoeffel, D. Dalury, J. B. Mason, J. Murphy, and S. Himden, "In-vivo alignment comparing patient specific instrumentation with both conventional and computer assisted surgery (CAS) instrumentation in total knee arthroplasty," Journal of Arthroplasty, vol. 29, no. 2, pp. 343-347, 2014.

[65] B. Boonen, M. G. M. Schotanus, B. Kerens, W. van der Weegen, R. A. M. van Drumpt, and N. P. Kort, "Intra-operative results and radiological outcome of conventional and patientspecific surgery in total knee arthroplasty: a multicentre, randomised controlled trial," Knee Surgery, Sports Traumatology, Arthroscopy, vol. 21, no. 10, pp. 2206-2212, 2013.

[66] K. Daniilidis and C. O. Tibesku, "A comparison of conventional and patient-specific instruments in total knee arthroplasty," International Orthopaedics, vol. 38, no. 3, pp. 503-508, 2014.

[67] W. G. Hamilton, N. L. Parks, and A. Saxena, "Patient-specific instrumentation does not shorten surgical time: a prospective, randomized trial," Journal of Arthroplasty, vol. 28, no. 8, pp. 96100, 2013.

[68] A. Kotela and I. Kotela, "Patient-specific computed tomography based instrumentation in total knee arthroplasty: a prospective randomized controlled study," International Orthopaedics, vol. 38, no. 10, pp. 2099-2107, 2014.

[69] S. Parratte, G. Blanc, T. Boussemart, M. Ollivier, T. Le Corroller, and J.-N. Argenson, "Rotation in total knee arthroplasty: no difference between patient-specific and conventional instrumentation," Knee Surgery, Sports Traumatology, Arthroscopy, vol. 21, no. 10, pp. 2213-2219, 2013.

[70] R. Russell, T. Brown, M. Huo, and R. Jones, "Patient-specific instrumentation does not improve alignment in total knee arthroplasty," Journal of Knee Surgery, vol. 27, no. 06, pp. 501504, 2014.

[71] E. Thienpont, P. E. Schwab, and P. Fennema, "A systematic review and meta-analysis of patient-specific instrumentation for improving alignment of the components in total knee replacement," Bone and Joint Journal B, vol. 96, no. 8, pp. 10521061, 2014.

[72] P. B. Voleti, M. J. Hamula, K. D. Baldwin, and G.-C. Lee, "Current data do not support routine use of patient-specific instrumentation in total knee arthroplasty," Journal of Arthroplasty, vol. 29, no. 9, pp. 1709-1712, 2014.

[73] B. J. Vundelinckx, L. Bruckers, K. De Mulder, J. De Schepper, and G. Van Esbroeck, "Functional and radiographic short-term outcome evaluation of the visionaire system, a patient-matched instrumentation system for total knee arthroplasty," Journal of Arthroplasty, vol. 28, no. 6, pp. 964-970, 2013.

[74] M. Pietsch, O. Djahani, M. Hochegger, F. Plattner, and S. Hofmann, "Patient-specific total knee arthroplasty: the importance of planning by the surgeon," Knee Surgery, Sports Traumatology, Arthroscopy, vol. 21, no. 10, pp. 2220-2226, 2013.

[75] A. Sassoon, D. Nam, R. Nunley, and R. Barrak, "Systematic review of patient-specific instrumentation in total knee arthroplasty: new but not improved," Clinical Orthopaedics and Related Research, vol. 473, no. 1, pp. 151-158, 2015.

[76] C. Scholes, V. Sahni, S. Lustig, D. A. Parker, and M. R. J. Coolican, "Patient-specific instrumentation for total knee arthroplasty does not match the pre-operative plan as assessed by intra-operative computer-assisted navigation," Knee Surgery, Sports Traumatology, Arthroscopy, vol. 22, no. 3, pp. 660-665, 2014.

[77] M. P. Abdel, S. Parratte, G. Blanc et al., "No benefit of patient-specific instrumentation in TKA on functional and gait outcomes: a randomized clinical trial," Clinical Orthopaedics and Related Research, vol. 472, no. 8, pp. 2468-2476, 2014.

[78] B. A. Rebal, O. M. Babatunde, J. H. Lee, J. A. Geller, D. A. Patrick, and W. Macaulay, "Imageless computer navigation in total knee arthroplasty provides superior short term functional outcomes: a meta-analysis," Journal of Arthroplasty, vol. 29, no. 5, pp. 938944, 2014.

[79] T. Cheng, S. Zhao, X. Peng, and X. Zhang, "Does computerassisted surgery improve postoperative leg alignment and implant positioning following total knee arthroplasty? A metaanalysis of randomized controlled trials?" Knee Surgery, Sports Traumatology, Arthroscopy, vol. 20, no. 7, pp. 1307-1322, 2012.

[80] D. Hernández-Vaquero, A. Suarez-Vazquez, and S. IglesiasFernandez, "Can computer assistance improve the clinical and functional scores in total knee arthroplasty?" Clinical Orthopaedics and Related Research, vol. 469, no. 12, pp. 34363442, 2011.

[81] K. Ishida, T. Matsumoto, N. Tsumura et al., "Mid-term outcomes of computer-assisted total knee arthroplasty," Knee Surgery, Sports Traumatology, Arthroscopy, vol. 19, no. 7, pp. 1107-1112, 2011.

[82] J. M. Spencer, K. Sloan, R. J. Beaver, S. K. Chauhan, and A. Taylor, "Computer navigation versus conventional total knee replacement: no difference in functional results at two years," Journal of Bone \& Joint Surgery-British Volume, vol. 89, no. 4, pp. 477-480, 2007.

[83] G. Matziolis, D. Krocker, U. Weiss, S. Tohtz, and C. Perka, "A prospective, randomized study of computer-assisted and conventional total knee arthroplasty. Three-dimensional evaluation of implant alignment and rotation," The Journal of Bone \& Joint Surgery-American Volume, vol. 89, no. 2, pp. 236-243, 2007.

[84] R. Decking, Y. Markmann, T. Mattes, W. Puhl, and H. P. Scharf, "On the outcome of computer-assisted total knee replacement," Acta Chirurgiae Orthopaedicae et Traumatologiae Cechoslovaca, vol. 74, no. 3, pp. 171-174, 2007.

[85] D. R. Lionberger, C. L. Crocker, and V. Chen, "Patient specific instrumentation," The Journal of Arthroplasty, vol. 39, no. 9, pp. 1699-1704, 2014.

[86] C. O. Tibesku, P. Hofer, W. Portegies, C. J. M. Ruys, and P. Fennema, "Benefits of using customized instrumentation in total knee arthroplasty: results from an activity-based costing model," Archives of Orthopaedic and Trauma Surgery, vol. 133, no. 3, pp. 405-411, 2013.

[87] J. J. Jauregui, J. J. Cherian, B. H. Kapadia et al., "Patient-specific instrumentation in total knee arthroplasty," Journal of Knee Surgery, vol. 27, no. 3, pp. 177-183, 2014.

[88] J. D. Slover, H. E. Rubash, H. Malchau, and J. A. Bosco, "Costeffectiveness analysis of custom total knee cutting blocks," The Journal of Arthroplasty, vol. 27, no. 2, pp. 180-185, 2012.

[89] R. M. Nunley, B. S. Ellison, E. L. Ruh et al., "Are patient-specific cutting blocks cost-effective for total knee arthroplasty?" Clinical Orthopaedics and Related Research, vol. 470, no. 3, pp. 889894, 2012.

[90] R. C. Wasielewski, D. D. Galat, and R. D. Komistek, "Correlation of compartment pressure data from an intraoperative sensing 
device with post-operative fluoroscopic kinematic results in TKA patients," Journal of Biomechanics, vol. 38, no. 2, pp. 333339, 2005.

[91] M. W. Roche, L. C. Elson, and C. R. Anderson, "A novel technique using sensor-based technology to evaluate tibial tray rotation," Orthopedics, vol. 38, no. 3, pp. e217-e222, 2015.

[92] K. Gustke, "Use of smart trials for soft-tissue balancing in total knee replacement surgery," The Journal of Bone \& Joint Surgery-British Volume, vol. 94, no. 11, pp. 147-150, 2012.

[93] A. Anastasiadis, E. Magnissalis, and A. Tsakonas, "A novel intraoperative sensor for soft tissue balancing in total knee arthroplasty," Journal of Medical Engineering and Technology, vol. 34, no. 7-8, pp. 448-454, 2010.

[94] R. C. Wasielewski, D. D. Galat, and R. D. Komistek, "An intraoperative pressure-measuring device used in total knee arthroplasties and its kinematics correlations," Clinical Orthopaedics and Related Research, no. 427, pp. 171-178, 2004.

[95] D. D. D’Lima, S. Patil, N. Steklov, and C. W. Colwell, "Dynamic intraoperative ligament balancing for total knee arthroplasty," Clinical Orthopaedics and Related Research, no. 463, pp. 208212, 2007.

[96] K. A. Gustke, G. J. Golladay, M. W. Roche, L. C. Elson, and C. R. Anderson, "A new method for defining balance: promising short-term clinical outcomes of sensor-guided TKA," Journal of Arthroplasty, vol. 29, no. 5, pp. 955-960, 2014.

[97] K. A. Gustke, G. J. Golladay, M. W. Roche, G. J. Jerry, L. C. Elson, and C. R. Anderson, "Increased satisfaction after total knee replacement using sensor-guided technology," Bone and Joint Journal, vol. 96B, no. 10, pp. 1333-1338, 2014.

[98] G. Golladay, G. Jerry, K. Gustke, M. Roche, L. Elson, and C. Anderson, "Post-operative weight gain after total knee arthroplasty: prevalence and its possible attenuation using intraoperative sensors," Reconstructive Review, vol. 4, no. 1, pp. 38-41, 2014.

[99] K. A. Gustke, "Soft tissue and alignment correction; The use of smart trials in total knee replacement," The Bone \& Joint Journal, vol. 96, no. 11, supplement, pp. 1-6, 2014.

[100] K. A. Gustke, G. J. Golladay, M. W. Roche, L. C. Elson, and C. R. Anderson, "Primary TKA patients with quantifiably balanced soft-tissue achieve significant clinical gains sooner than unbalanced patients," Advances in Orthopedics, vol. 2014, Article ID 628695, 6 pages, 2014.

[101] W. Anderl, L. Pauzenberger, R. Kölblinger et al., "Patientspecific instrumentation improved mechanical alignment, while early clinical outcome was comparable to conventional instrumentation in TKA," Knee Surgery, Sports Traumatology, Arthroscopy, 2014.

[102] T. Cheng, G. Zhang, and X. Zhang, "Imageless navigation system does not improve component rotational alignment in total knee arthroplasty," Journal of Surgical Research, vol. 171, no. 2, pp. 590-600, 2011.

[103] T. van Strien, E. van der Linden-van der Zwaag, B. Kaptein, A. van Erkel, E. valstar, and R. Nelissen, "Computer assisted versus conventional cemented total knee prostheses alignment accuracy and micromotion of the tibial component," International Orthopaedics, vol. 33, no. 5, pp. 1255-1261, 2009.

[104] B. M. Stronach, C. E. Pelt, J. Erickson, and C. L. Peters, "Patientspecific total knee arthroplasty required frequent surgeondirected changes," Clinical Orthopaedics and Related Research, vol. 471, no. 1, pp. 169-174, 2013. 


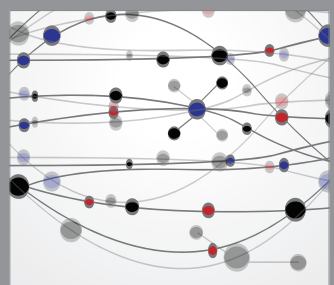

The Scientific World Journal
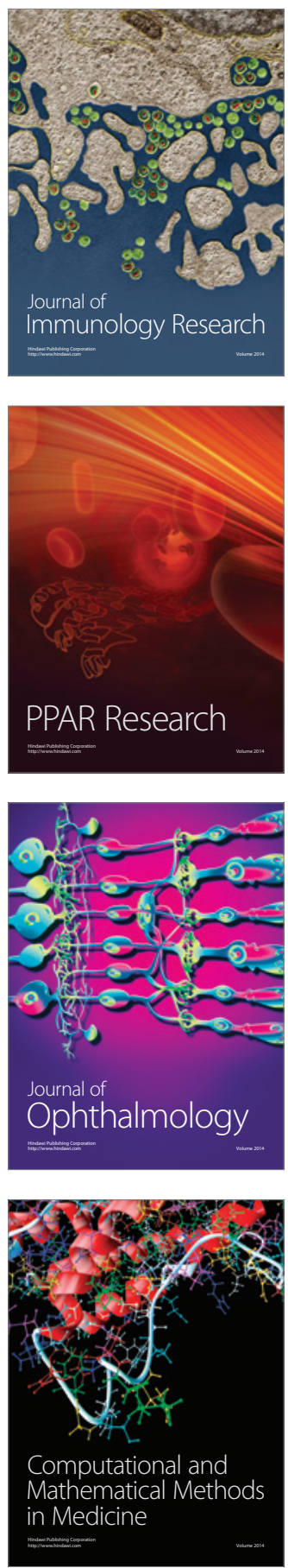

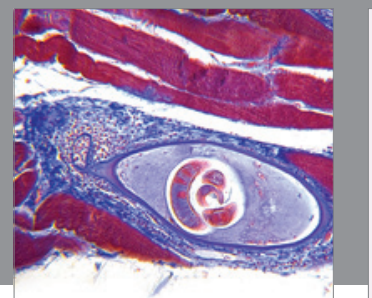

Gastroenterology

Research and Practice
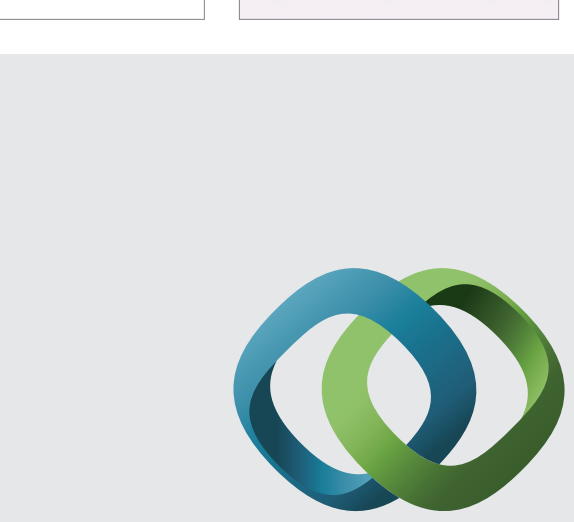

\section{Hindawi}

Submit your manuscripts at

http://www.hindawi.com
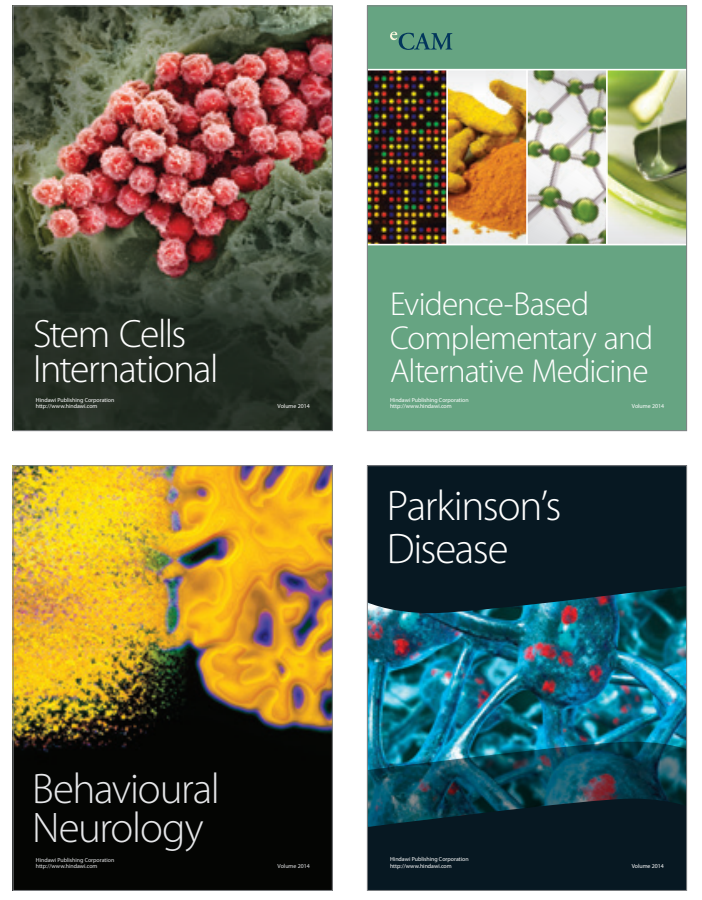
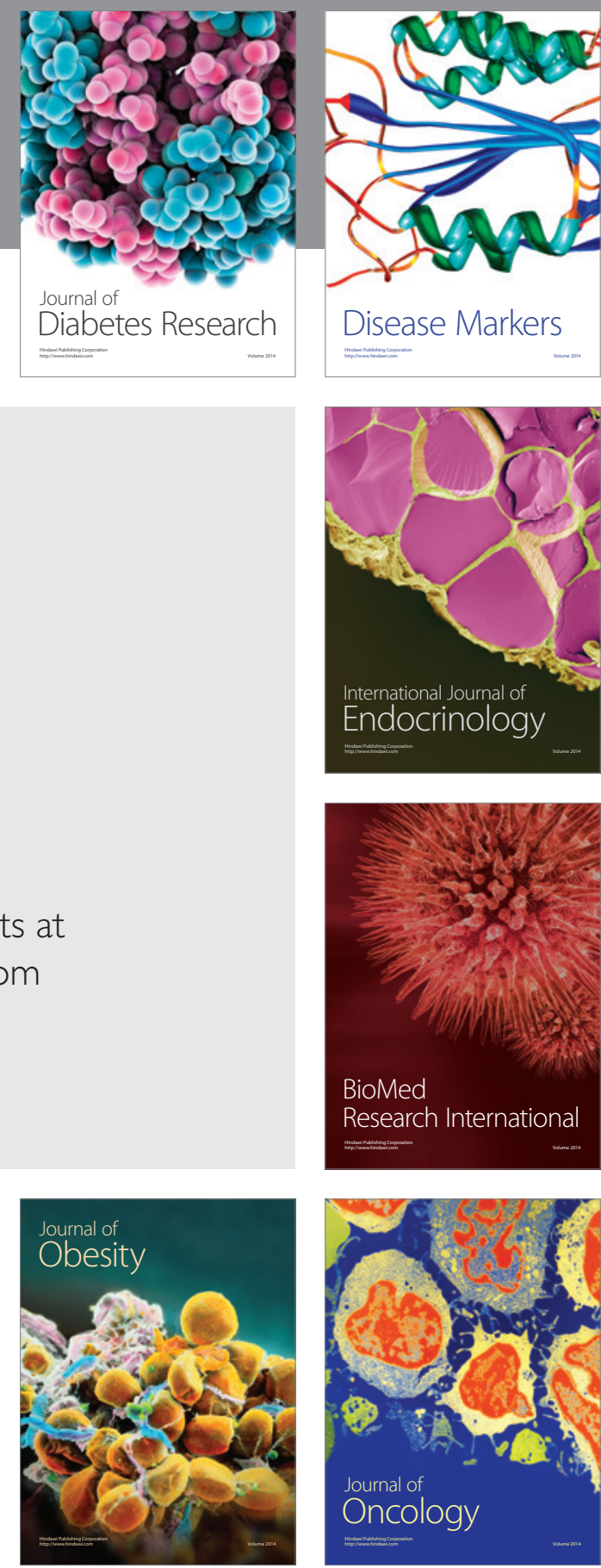

Disease Markers
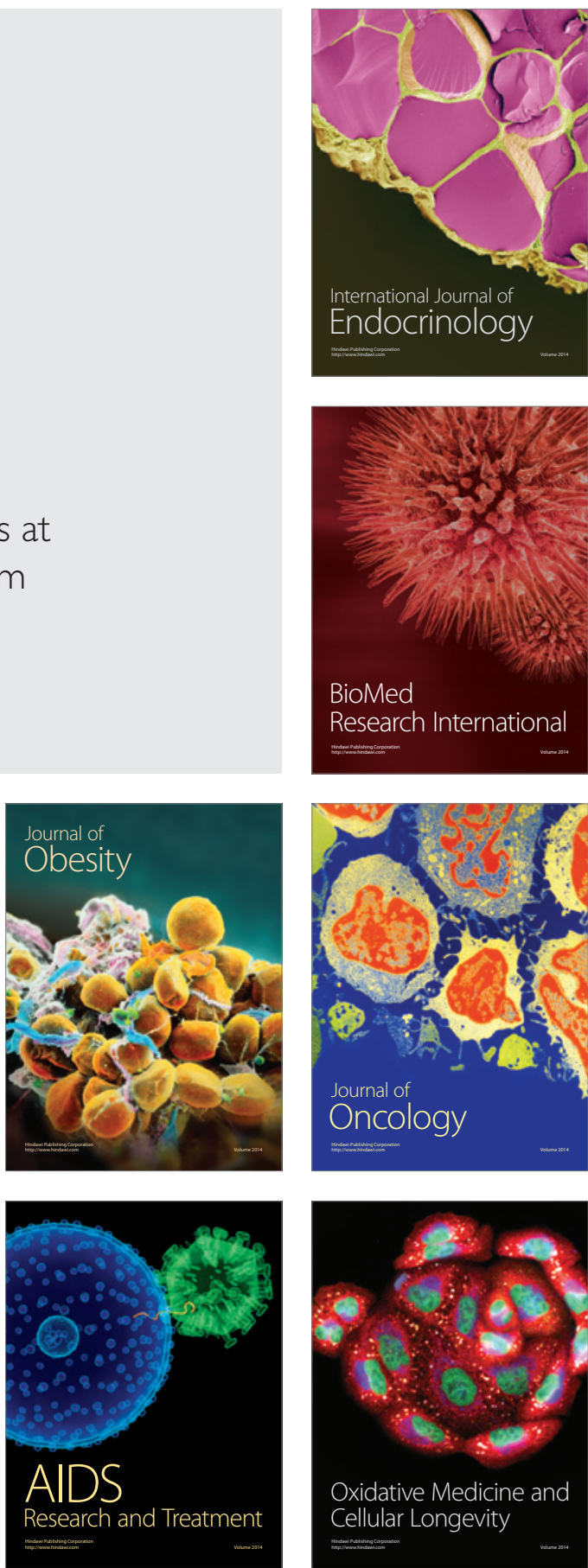